Sir,

\section{Reply to GW Aylward}

I would like to thank Bill Aylward and Catey Bunce for their helpful comments. Our study was a small clinical study which showed that noncontact slit-lamp examination was less reliable in my hands when compared to indirect ophthalmoscopy with scleral indentation in identifying retinal tears. I believe that peripheral retinal examination is enhanced by scleral indentation. In another surgeon's hands things may be different and I await the study, with or without statistical analysis, which will take an alternative point of view.

R Goble, M Natkunarajah and C Goldsmith

Ipswich Hospital

Department of Ophthalmology

Heath Road Ipswich, Suffolk IP4 5PD UK

Correspondence: R Goble

Tel: 0441473703504

Fax: 0441473703528

E-mail: richard.goble@ipswichhospital.nhs.uk

Eye (2005) 19, 474. doi:10.1038/sj.eye.6701520

Published online 6 August 2004

Sir,

Diagnostic effectiveness of noncontact slit-lamp examination in the identifying of retinal tears

We read with interest the article by Natkunarajah et al. ${ }^{1}$ We agree that indirect ophthalmoscopy with indentation remains the gold standard for the detection of retinal breaks.

It is not clear if the initial examination by trainees was performed on slit lamp biomicroscope or with a binocular indirect ophthalmoscope? It would be easy to pick up relatively 'non-peripheral' tears on slit-lamp biomicroscopy. The authors acknowledge that the high pick-up rate by the consultant using the slit-lamp biomicroscopy could be attributable to the fact that he/she was aware of the presence of a retinal tear. A better alternative would be to examine all patients with symptomatic PVD with slit-lamp biomicroscopy. These patients should then be re-examined by the same observer with an indirect ophthalmoscopy to see whether any more tears can be detected. This would avoid the examination bias mentioned in the article and may be a truer reflection of the sensitivity of slit-lamp biomicroscopy in the detection of peripheral retinal tears.
We are concerned that in majority of consulting offices, no flat couches are available to lie the patient down for examination with binocular ophthalmoscope and indentation. There is a tendency to examine the patients with a $90 \mathrm{D}$ lens and less incentive to perform indirect ophthalmoscopy that might involve taking the patient to another room. The Royal College Higher Specialist Training curriculum only requires assistance in vitreoretinal procedures and none to be performed. With fewer opportunities to perform scleral buckling surgery, trainees are less likely to gain experience in indirect ophthalmoscopy and indentation. In most units, rigorous preoperative evaluation using the binocular indirect ophthalmoscope and detailed retinal drawing has given way to intraoperative search for retinal breaks. With this trend, newly trained consultants are likely to be less proficient in indirect ophthalmoscopy and as an extension, less likely to pass on this valuable skill to their juniors.

\section{References}

1 Natkunarajah M, Goldsmith C, Goble R. Diagnostic effectiveness of non-contact slit lamp examination in the identifying of retinal tears. Eye 2003; 17: 607-609.

J Shankar and N Kaushik

Department of Ophthalmology

Maelor Hospital Wrexham LL13 7TD, UK

Correspondence: NC Kaushik

Tel: + 441978725829

E-mail: NIKHIL.KAUSHIK@new-tr.wales.nhs.uk

Eye (2005) 19, 474. doi:10.1038/sj.eye.6701521

Published online 6 August 2004

Sir,

Reply to J Shankar and N Kaushik

I would like to thank Messrs Shankar and Kaushik for their interesting letter. Their suggestion for a 'better alternative' was in fact what was undertaken. A single examiner (RRG) first examined the patient at the slit lamp, recorded his findings, and then used the indirect ophthalmoscope before completing a second retinal diagram.

I apologise if this is unclear in the text.

RR Goble, M Natkunarajah and Craig Goldsmith 